\title{
Neumonías de repetición en escolar con situs inversus totalis y sospecha de discinesia ciliar primaria
}

\author{
Recurring pneumonia in a school-age patient with situs inversus \\ totalis and suspected primary ciliary dyskinesia
}

\author{
Alicia Martínez-Sebastián* \\ * Servicio de Pediatría, Hospital Universitario Doctor Peset. Valencia, España.
}

\begin{abstract}
RESUMEN
Introducción: El situs inversus totalis se caracteriza por la posición invertida de los órganos torácicos y abdominales con respecto al plano sagital. En general, el diagnóstico se realiza de forma casual dada la ausencia de síntomas, pudiendo asociarse con malformaciones cardiacas, digestivas, renales y de vías respiratorias, siendo la discinesia ciliar primaria la más frecuente. Caso clínico: Varón de 10 años, con diagnóstico previo de situs inversus totalis, quien acude a urgencias por tos, dolor torácico, dificultad respiratoria y fiebre. Se realizó diagnóstico de neumonía recurrente en lóbulo inferior izquierdo. Dado que fue el tercer episodio de neumonía, se sospechó de síndrome de Kartagener (una forma de discinesia ciliar primaria) que se descartó por no presentar bronquiectasias ni sinusitis crónica. Conclusiones: El situs inversus totalis puede asociarse a múltiples condiciones, incluyendo trastornos de vías respiratorias altas y bajas, como consecuencia de discinesia ciliar primaria como el síndrome de Kartagener.

Palabras clave: Situs inversus totalis, discinesia ciliar primaria, Kartagener, neumonías.
\end{abstract}

\section{INTRODUCCIÓN}

El situs inversus totalis (SIT) se caracteriza por la posición invertida de los órganos torácicos y abdominales con respecto al plano sagital, como resultado de anomalías en la rotación del tubo, cardiaco durante la tercera semana del desarrollo embriológico; este periodo corresponde a la etapa de gastrulación en la que

\begin{abstract}
Introduction: Situs inversus totalis is characterized by the inverted position of the thoracic and abdominal organs with respect to the sagittal plane. In general, the diagnosis is made incidentally, given the absence of symptoms. Situs inversus totalis can be associated with cardiac, digestive, kidney, and respiratory malformations, but the most common is primary ciliary dyskinesia. Clinical case: 10-year-old male patient diagnosed with situs inversus totalis who came to the emergency room for cough, chest pain, respiratory distress and fever. Recurrence of pneumonia in the left lower lobe was identified on a third occasion, which raised suspicion of Kartagener syndrome (a form of primary ciliary dyskinesia), which was ruled out because the patient did not present bronchiectasis or chronic sinusitis. Conclusions: Situs inversus totalis can be associated with multiple conditions, including upper and lower respiratory disorders, as a consequence of primary ciliary dyskinesia, such as Kartagener syndrome.
\end{abstract}

Keywords: Situs inversus totalis, primary ciliary dyskinesia, Kartagener, pneumonias.

se establecen los ejes derecha-izquierda del embrión. ${ }^{1}$ Tiene una etiología multifactorial en la que se cree que están involucrados factores ambientales, maternos y genéticos. ${ }^{2}$

Es una entidad poco frecuente, con una prevalencia estimada de 1/10,000 nacimientos, en una relación mujer-hombre 1:1.5, sin predilección racial. Recientemente se han identificado numerosos genes implicados

Correspondencia: Alicia Martínez-Sebastián, aliciamarsebastian@gmail.com

Citar como: Martínez-Sebastián A. Neumonías de repetición en escolar con situs inversus totalis y sospecha de discinesia ciliar primaria. Rev Mex Pediatr. 2021; 88(2): 71-74. https://dx.doi.org/10.35366/101281 
como el ZIC3 [MIM:300265], CCDC11 [MIM:614759], CFAP52 [MIM:609804], NME7 [MIM:613465] y el PKD1L1 [MIM:609721]. ${ }^{2,3}$

En la edad pediátrica, con frecuencia el diagnóstico se realiza de forma casual dada la ausencia de síntomas, ya que sólo $5-10 \%$ se asocian a malformaciones cardiovasculares congénitas, siendo la discinesia ciliar primaria (DCP) la patología que con más frecuencia se relaciona. La DCP o síndrome del cilio inmóvil incluye diversas anomalías ciliares: aplasia, inmovilidad y discinesia ciliar, y es la forma de expresión más común de un conjunto de enfermedades conocidas como ciliopatías. Es una enfermedad hereditaria autosómica recesiva que involucra mutaciones que alteran los cilios móviles, y en la que se han identificado 12 genes. Éstos se expresan en diferentes áreas, por lo que la disrupción de la motilidad ciliar puede causar infecciones recurrentes del pulmón, oído medio y senos paranasales. ${ }^{4}$

La ineficacia de los cilios nodales embrionarios hace que la asimetría de los órganos internos se disponga al azar dando lugar, en $50 \%$ de estos pacientes, a un SIT. $\mathrm{Su}$ presencia, junto con sinusitis paranasales y bronquiectasias, se conoce como síndrome de Kartagener, el cual es un subgrupo de la DCP; este diagnóstico se sospechó en un primer momento en nuestro paciente. ${ }^{4}$

El objetivo de esta comunicación es revisar las claves diagnósticas del SIT y resaltar la importancia de su diagnóstico temprano enfocado en las complicaciones respiratorias.

\section{CASO CLÍNICO}

Varón de 10 años procedente de Pakistán que acude a urgencias por tos y dolor torácico de 72 h de evolución, asociados a dificultad respiratoria y fiebre hasta de 38 ${ }^{\circ} \mathrm{C}$ desde hace 24 horas.

Tiene como antecedente madre de 44 años con diagnóstico de tuberculosis latente hace dos años, QuantiFERON positivo y con radiografía de tórax normal, recibiendo isoniacida durante nueve meses.

Como antecedentes personales se destaca que el paciente ya había sido diagnosticado con SIT y dextrocardia; dos episodios de neumonía en lóbulo inferior izquierdo en los últimos ocho meses que fueron tratados ambulatoriamente, además de prueba de Mantoux negativa. Sin episodios de otitis o sinusitis previos.

A la exploración física el paciente se encuentra taquipneico, con saturación basal de $96 \%$; a la auscultación se identifica disminución de los ruidos respiratorios y estertores crepitantes en los $2 / 3$ inferiores de hemitórax izquierdo.
Se realiza analítica sanguínea, proteína $\mathrm{C}$ reactiva $94 \mathrm{mg} / \mathrm{L}$, procalcitonina $0.46 \mathrm{ng} / \mathrm{mL}, \mathrm{Hb} 11.7 \mathrm{~g} / \mathrm{dL}$, hematocrito $35.6 \%$, leucocitos 20,100, neutrófilos 17,400 (86.4\%). Hemocultivo negativo a los cinco días de incubación. Serología negativa para virus respiratorios, incluido micoplasma. Radiografía de tórax (Figura 1) en la que se observa consolidación en lóbulo inferior izquierdo, y opacidades tubulares en esa misma localización, que podrían corresponder con bronquiectasias en paciente con dextrocardia e inversión de vísceras abdominales; este hallazgo junto con las infecciones respiratorias de repetición hicieron sospechar de un síndrome de Kartagener, por lo que se amplía el estudio con tomografía axial computarizada de alta resolución (TACAR) torácica (Figura 2), descartando la existencia de bronquiectasias.

Durante su ingreso, test del sudor negativo, por lo que se descartó fibrosis quística; ecografía abdominal normal, exceptuando la inversión de vísceras abdominales. En ecocardiografía el hallazgo fue de dextrocardia especular clásica, sin malformaciones cardiacas asociadas. Espirometría normal con FEV1 86\%.

Se instaura tratamiento con ampicilina $150 \mathrm{mg} / \mathrm{kg} /$ día hasta resultado negativo de hemocultivo, pasando a amoxicilina $80 \mathrm{mg} / \mathrm{kg} /$ día vía oral durante siete días,

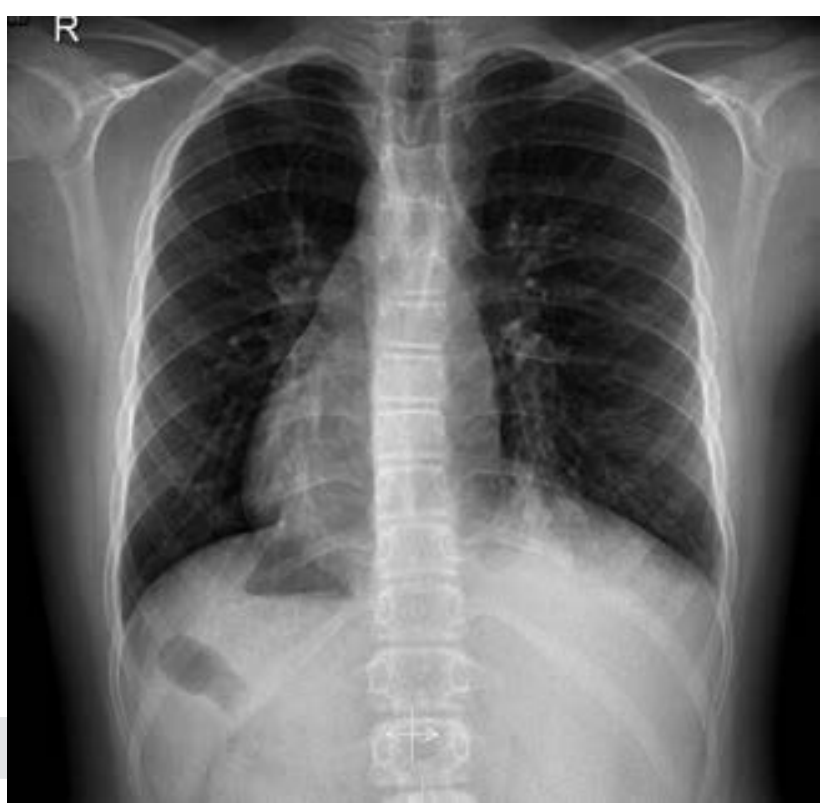

Figura 1: Radiografía posteroanterior de tórax en la que se observa la silueta cardiaca localizada en el hemitórax derecho, la cámara gástrica con contenido aéreo en la región subdiafragmática derecha y la sombra hepática en la región subdiafragmática izquierda y neumonía en lóbulo inferior izquierdo. 
además de salbutamol nebulizado, con mejoría clínica progresiva.

Tras realizar TACAR se descarta Kartagener, porque no cumple tríada del síndrome (bronquiectasias + sinusitis paranasal + SIT). No obstante, ante las tres neumonías, solicitamos estudio genético para determinar la presencia de patrones genéticos descritos para discinesia ciliar primaria así como estudio confirmatorio en células epiteliales nasales o bronquiales mediante la observación de cambios ultraestructurales por microscopía electrónica. Sin embargo, el paciente regresó a su país de origen, por lo que no se pudo completar su evaluación.

\section{DISCUSIÓN}

Entre la lateralidad habitual (situs solitus) y la imagen completa en espejo (situs inversus) se encuentra el situs ambiguo o heterotaxia (transposición especular parcial de los órganos intratorácicos o intraabdominales sobre el eje sagital); estas dos últimas condiciones pueden asociarse a múltiples malformaciones, por lo que forman parte del examen ultrasonográfico rutinario prenatal. El SIT, entidad central en nuestro caso, es una variante anatómica poco frecuente, en la cual existe inversión completa del corazón y de los órganos abdominales creando una imagen en espejo, dispuesta en un eje de izquierda a derecha. ${ }^{4}$

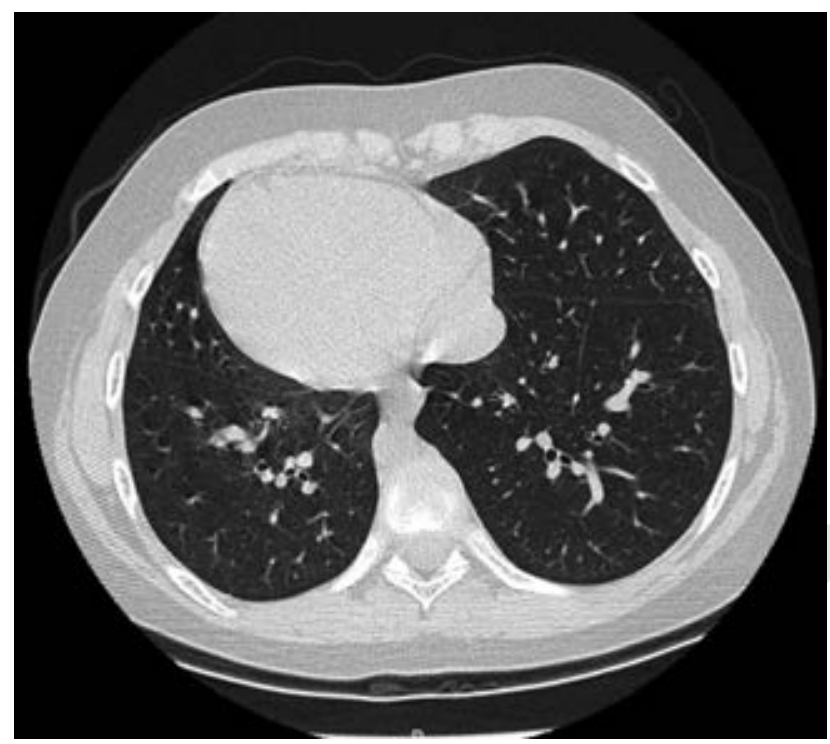

Figura 2: Tomografía axial computarizada de alta resolución (TACAR) torácica sin presencia de bronquiectasias.
Sólo 5-10\% de los pacientes con SIT presentan cardiopatías asociadas y malformaciones cardiovasculares iniciando con síntomas atribuibles a estas patologías, lo que facilita el diagnóstico precoz de esta entidad. ${ }^{5} \mathrm{La}$ mayoría de los pacientes se encuentran asintomáticos y la dextrocardia suele suponer un hallazgo casual en la exploración física o radiografía de tórax de rutina, tal y como ocurrió en nuestro caso, pudiendo retrasarse el diagnóstico incluso hasta la edad adulta.

En la exploración física podemos detectar cambios en los focos de auscultación cardiaca. Se requiere de ecocardiografía para establecer el situs y a la vez descartar patología cardiaca estructural como la tetralogía de Fallot, trasposición de grandes vasos, estenosis pulmonar, o defectos en el tabique auricular o ventricular asociados con la dextrocardia. Además, la ecografía abdominal ayuda a localizar la posición de las vísceras abdominales y detectar hernia diafragmática, asplenia o poliesplenia, alteraciones renales (como agenesia renal o riñón en herradura) o de la vía biliar.,5,6

A nivel respiratorio puede ocurrir sinusitis, neumonías de repetición, o el desarrollo de bronquiectasias producidas por la ausencia de transporte mucociliar que provocará estasis de las secreciones al estar la estructura ciliar alterada dificultando su aclaramiento, ocasionando el síndrome de Kartagener, ${ }^{7}$ como se sospechó en nuestro paciente. Las alteraciones del cilio, conocidas como DCP o síndrome del cilio inmóvil, están asociadas hasta en 50\% de los casos con el SIT, y se postula que puede haber un vínculo que explique esta relación entre el cilio móvil y el eje de izquierda a derecha, que estaría causado por un flujo anormal generado por los monocilios móviles en el nodo embrionario, lo cual es necesario para establecer la lateralidad de estos defectos. ${ }^{4}$ Por estos motivos, la infección bronquial puede iniciarse precozmente, siendo ésta la mayor causa de morbilidad y mortalidad de esta entidad, por lo que su reconocimiento precoz junto con el inicio de un tratamiento oportuno retrasarían las posibles secuelas. La sospecha diagnóstica de la DCP o de los subtipos asociados, como el síndrome de Kartagener, se deberá confirmar con el estudio de la disfunción o inmovilidad ciliar, así como la existencia de alteraciones ultraestructurales en el cilio, mediante muestras de células ciliadas procedentes de la mucosa nasal (extraídas por raspado/cepillado) o bronquial. ${ }^{8}$

\section{REFERENCIAS}

1. Juncos M, Ros MA, Maravall M, Álvarez-Pitti J. Situs inversus totalis. A propósito de 2 casos clínicos. Rev Chil Pediatr. 2014; 85(3): 344-350. 
2. Postema MC, Carrion-Castillo A, Fisher SE, Vingerhoets G, Francks $\mathrm{C}$. The genetics of situs inversus without primary ciliary dyskinesia. Sci Rep. 2020; 10(1): 3677.

3. Li AH, Hanchard NA, Azamian M, D’Alessandro LCA, CobanAkdemir Z, Lopez KN et al. Genetic architecture of laterality defects revealed by whole exome sequencing. Eur J Hum Genet. 2019; 27(4): 563-573.

4. Montaner AE, Carceller MA. Discinesia ciliar primaria. An Pediatr Contin. 2013; 11(1): 38-45.

5. Aljure Reales VJ, Álvarez Gallego GC, Ávila Espitia NC, Arrieta Coley A, Ángel Suárez OG. Situs inversus totalis: revisión de tema con aproximación a la genética y reporte de casos. Rev Colomb Cardiol. 2017; 24(1): 40-47.
6. Chen W, Guo Z, Qian L, Wang L. Comorbidities in situs inversus totalis: a hospital-based study. Birth Defects Res. 2020; 112(5): 418-426.

7. Serapinas D, Staikunien J, Barkauskiene D, Jackute J, Sakalauskas $R$. Una regresión poco común de los síntomas de un síndrome de Kartagener. Arch Bronconeumol. 2013; 49(1): 28-30.

8. Armengot Carcellera M, Carda Batallab C, Escribanoc A, Samperd GJ. Estudio del transporte mucociliar y de la ultraestructura ciliar nasales en pacientes con síndrome de Kartagener. Arch Bronconeumol. 2005; 41(1): 11-15.

Conflicto de intereses: La autora declara que no tiene. 